\title{
Physiological basis of Growth and Development among Children and Adolescent in Relation to Physical Activity
}

\author{
Pradeep Singh Chahar* \\ Department of Physical Education and Sports, Manipal University, Jaipur, India \\ *Corresponding author: pradeepchahar84@gmail.com
}

Received August 04, 2014; Revised August 14, 2014; Accepted August 21, 2014

\begin{abstract}
Physical inactivity is one of the leading causes of serious chronic disease which keeps on increasing with high rate. Physical activity plays an important role in enhancing the various physiological dimensions of growth and development in children and adolescents. Physical activity of different duration will enhance cardiovascular health, bone ossification, muscle growth and endocrine glands secretion. Data suggested that anthropometry is a key component for growth and development assessment in children and adolescent especially body mass index, which is quite effective and reliable. Without engaging the children's in physical activity leads to increased chances of obesity, cardiovascular diseases, cancer and diabetes in future and that fastenings the attention of fitness personal and policy makers. Developing good practices early in life, will benefited in future. Hence, parents, teachers and policymakers have to plan accordingly to make their child healthy and fit. This article reviews the available literature regarding the physiological basis of growth and development of children and adolescents in relation to physical activity along with various anthropometric assessment methods.
\end{abstract}

Keywords: physiological, growth, development, physical activity, children, adolescents

Cite This Article: Pradeep Singh Chahar, "Physiological basis of Growth and Development among Children and Adolescent in Relation to Physical Activity.” American Journal of Sports Science and Medicine, vol. 2, no. 5A (2014): 17-22. doi: 10.12691/ajssm-2-5A-5.

\section{Introduction}

Development is a lifelong process of physical, behavioral, cognitive, and emotional growth and change. In the early stages of life-from babyhood to childhood, childhood to adolescence, and adolescence to adulthoodenormous changes take place. Throughout the process, each person develops attitudes and values that guide choices, relationships, and understanding [1]. The beginning of biological growth and development during adolescence is signified by the onset of puberty, which is often defined as the physical transformation of a child into an adult [2]. Each child's growth and developmental progress will be unlike any other child's, but their acquisition of motor skills will occur in the same order or sequence as other children. The development of these skills depends on the child's genetic makeup, environmental and cultural factors, and everyday experiences [3].

Physical activity is defined as any bodily movement produced by skeletal muscles that require energy expenditure. Physical inactivity has been identified as the fourth leading risk factor for global mortality causing an estimated 3.2 million deaths globally [4].The development of healthy eating behaviors and physical activity patterns helps to optimize health status and promote mental and physical wellbeing [5]. Physical activity during the growth period appears to be necessary for normal growth and development of the skeleton, musculature and oxygen- carrying organs [6]. The value of physical activity to normal growth and development, including the health and well- being of children and adolescents is undisputed $[7,8]$. Habitual physical activity established during the early years may provide the greatest likelihood of impact on mortality and longevity. It is evident that environmental factors need to change if physical activity strategies are to have a significant impact on increasing habitual physical activity levels in children and adolescents [9]. Participation in physical activity during childhood could have important implications for adulthood [10,11,12].

Human growth physiology can be considered to include the dynamic period beginning with cleavage of the zygote and ending with completion of adolescence, marked by the end of long bone growth. Childhood growth is also characterized by a rapid change in body proportions, when the legs grow faster than the trunk, and both grow much faster than the head in proportion to overall body length [13]. It is during adolescence that the greatest physiologic differences exist mainly because of the wide variations in the timing and tempo of the pubertal growth spurt in normally growing boys and girls [14]. The ultimate objective of this research paper is to highlight the important role of physical activity on physiology of growth and development among children and adolescent.

\section{Physical Activity and Obesity}

Obesity is emerging as one of the most serious problem discern of the present century especially childhood obesity 
which is the major public health crunch globally that are on rise. According to WHO, 22 million children (under 5 years of age) are overweight [15]. Obesity during childhood and adolescence is a risk factor for type 2 diabetes mellitus in adulthood, even after accounting for adult obesity [16]. If energy intake consistently exceeds energy requirements there will be a progressive accumulation of body fat. Obesity may therefore result from either high-energy intake or low energy expenditure or a combination of both factors. A regulated reduction in energy intake will promote significant loss of body mass in the obese $[17,18]$. The treatment of overweight and obesity in children and adolescents requires a multidisciplinary, multi-phase approach, which includes engaging students in healthy eating and regular physical activity that can help lower their risk for obesity and related chronic diseases, including heart disease, cancer, and stroke; the three leading causes of death among adults aged 18 years or older $[19,20]$. Improving and intensifying efforts to promote physical activity and healthy eating is entirely consistent with the fundamental mission of schools: educating young people to become healthy, productive citizens who can make meaningful contributions to society [21]. In combination with family intervention and a moderate reduction in caloric intake, physical activity has produced significant reductions in the prevalence of childhood and adolescent obesity [22].

\section{Physical Activity and Skeletal Health}

The foundation for longer term skeletal health is established during childhood and adolescence. Physical activity represents a major mechanical loading factor for bone through a combination of growth (determining bone size), modelling (determining the shape of bone) and remodeling (maintaining the functional competence of bone) [23]. Peak Physical activity and normal growth are also positively associated with skeletal mineralization [24] and during childhood it may have long-lasting benefits on bone health [25].Growing bone responds to low or moderate exercise through significant additions of new bone in both cortical and trabecular moieties and results in adaptation through periosteal expansion and endo-cortical contraction. Intra-cortical activation frequency declines in growing bone in response to exercise, reducing porosity and the re-modelling space. These adaptations can be maintained into and throughout adulthood [26]. Since immature bones experience greater increase in bone formation than mature bones [27], adequate weightbearing physical activity has beneficial effects on bone health across the age spectrum especially those activities that generate relatively high-intensity loading forces, such as plyometrics, gymnastics, and high-intensity resistance training, augment bone mineral accrual in children and adolescents [28]. There is consistent evidence that weight -bearing exercise during youth contributes to increased peak bone mass [29,30,31] and provides the mechanical stimuli or 'loading' important for the maintenance of bone health and to minimize the rate of bone loss later in life [32]. Hence, physical activity and sports play an important role in preventing the child from different bone deformities.

\section{Physical Activity and Cardiovascular Health}

Over the school age years, a consistent decline in physical activity is seen, with males decreasing about $2.7 \%$ per year and females decreasing about $7.4 \%$ per year [33]. It has been also determined that increased left ventricular mass, which is an independent risk factor for cardiovascular disease in adults, is present in childhood [34],after adjustment for demographic factors, adolescents who engaged in relatively large amounts of vigorous physical activity tended to have a better cardiovascular fitness and a lower percentage of body fat than those who did not. In adults, there is convincing evidence to show that a sedentary lifestyle is associated with debilitative lipoprotein regulation [35], and a greater risk of cardiovascular disease and mortality in adults [36]. The prevalence of clustered (multiple) cardiovascular risk factors is lower in children and adolescents, who are physically active or fit. Good health in youth is easily lost by an unhealthy lifestyle in adulthood. An additional benefit of childhood physical activity is that it increases the likelihood of physical activity later in adulthood. [37]. School-age youth should participate daily in 60 minutes or more of moderate to vigorous physical activity that is developmentally appropriate, enjoyable, and involves a variety of activities [38].

\section{Physical Activity and Nervous Health}

Previous studies have shown that adolescent girls exhibit twice the prevalencerate of depressive symptoms compared to males in the same age group [39]. Prepubertal boys and girls are equally likely to show depressive symptoms, however, the high number of females with depressive symptoms arises after the age of 13 years [40]. Stress has become an ever-increasing and relevant problem in children [41]. Regular physical activity improves self-esteem, and reduces stress and anxiety [42]. Anxiety disorders are one of the most common mental health problems among children and youth. Children may be diagnosed with more than one anxiety disorder or with anxiety and other mental health challenges [43]. Case reports in adults have indicated that regular physical activity may be helpful in the treatment of panic attacks and phobias [44]. Most studies suggest that exercise programs are related to improvements in the selfesteem scores of participants [45]. Studies show that exercise benefits learning, memory and cognitive ability in numerous ways. There is abundant evidence that regular physical activity benefits the brains and bodies of schoolaged children [46]. Apart from all these importance, exercise also increases the flow of blood to the brain. The blood delivers oxygen and glucose, which the brain needs for heightened alertness and mental focus. Because of this, exercise makes it easier for children to learn and helps in creativity [47]. The positive effects of physical activity on academic achievement have been detected in mathematical subjects in particular. Participation in training as a member of sports and exercise clubs has been linked to good performance at school. Physical activity also has been found to have a positive effect on children's 
cognitive functions, such as memory, attention and general information processing and problem solving skills [48]. Researchers have found an association between physical fitness and the brain in 9- and 10-year-old children, those who are more fit tend to have a bigger hippocampus and perform better on a test of memory than their less-fit peers [49]. Therefore, exercise may serve as an effective tranquilizer. Studies revealed that $30 \mathrm{~min}$ of aerobic exercise reduces muscle tension by as much as does a dose of $400 \mathrm{mg}$ of meprobamate [50].

\section{Physical Activity and Endocrine Functioning}

The endocrine system is unique because it includes glands and hormones instead of just organs. The health of the endocrine system is essential to healthy body growth and physical or emotional development [51].Adolescence is a time of rapid growth caused by significant changes in hormone levels [52]. Exercise boosts the number of hormones circulating in our body and strengthens receptor sites on target organ cells [53]. Group jogging exercise may be effective in improving depressive state, hormonal response to stress of adolescent females with depressive symptoms [54]. Growth Hormone (GH) and Dehydroepiandrosterone sulfate (DHEAS) showed a slower decline in active individual than the inactive peers [55]. Regular exercise habit induces the secretion pattern of GH and DHEAS throughout the lifespan [56,57,58,59,60]. Exercise is known to cause perturbations in endocrine and metabolic systems in children and adolescents that may influence growth and development during puberty, yet careful characterization of these responses is only now being conducted [52].

\section{Physical Activity and Muscular Health}

Growth is accompanied by an increase in the number of myofibrils, myofilaments and sarcomeres, which lead to the elongation of muscles [61]. Muscle development is specific and only the muscle fibers that are engaged in the activity can increase in strength [62]. Changes in the muscles with growth and maturation can greatly affected by physical activity and exercise performance. Some of these changes are related to the muscle metabolic capability. This capability of the developing muscles shows higher oxidative enzyme activities in the children compared to those for adults [63]. Muscle mass accounts for $25 \%$ of total weight at birth and nearly $40 \%$ in adults. Most muscle growth occurs during puberty and is promoted by physical activity [61]. Muscle-strengthening activities make muscles to do more work than usual during activities of daily life. This is called "overload," and it strengthens the muscles [64]. Maturation of skeletal muscle fiber type at the time of puberty, specifically a pattern change from slow to fast twitch, might explain some of the differences in the metabolic responses to exercise between children and adults [65]. Research also revealed that regular participation in physical activity is associated with the stronger muscle in children and young people [66].

\section{Anthropometry and Assessment of Growth and Development}

The assessment of growth in children is important for monitoring health status, identifying deviations from normality and determining the effectiveness of interventions [67]. Anthropometry is a key component of nutritional status assessment in children as well as in adults. Comparing anthropometric data from children of different ages is complicated by the fact that children are still growing (We do not expect the height of a 5-year-old to be the same as the height of a 10-year-old!) [68]. But the question is which anthropometric variable is more reliable in comparison to others. One of study suggested that the validity of the anthropometric skin fold thickness in the obese children is low and BMI provides the best estimate of body fat [69]. The childhood obesity working group of the international obesity taskforce recommended the use of body mass index (BMI) cut off points to categorize children as normal weight, overweight, or obese based on age, gender, and BMI [70]. One of the study suggested that weight-for-height could be used for prepubertal adolescents and body mass index could be used for postpubertal adolescents [71]. A new function for egen has been developed to allow transformation of child anthropometric data to z-scores using the LMS (lambdamu-sigma) method. An additional function allows for children to be categorized according to body mass index (weight/height $^{2}$ ) using international cut off points recommended by the Childhood Obesity working group of the international obesity taskforce [68]. As per the WHO review head circumference-for-age is often used in clinical settings as part of health screening for potential developmental or neurological disabilities in infants and young children. Very small and very large circumferences are both indicative of health or developmental risk. Arm circumference-for-age is used as an alternative indicator of nutritional status when the collection of length/height and weight measurements is difficult, as happens in emergency humanitarian situations due to famine or refugee crises [72].

\section{Conclusion}

After over viewing the related literature, we may conclude that physical activity is considered as indispensable for healthy growth and development in children and adolescent. Regular physical activity in childhood not only improves health and quality of life but also enhances the physiological characteristics such as cardiovascular fitness, strength and bone density. Doing exercise regularly also prevents from different types of non-communicable diseases such as coronary heart disease, cancer, type 2 diabetes, pulmonary diseases etc. According to the World Health Organization, physical inactivity is one of the leading causes of major chronic diseases. Research suggested that Regular physical activity especially endurance exercise plays an important role in prevention of childhood obesity by enhancing the process of fatoxidation. Physical activities also have a significant role in keeping children and adolescent bone health optimum by enhancing mineralization or 
ossification process which results in increased peak bone mass.

Many studies reveal that adolescents who engaged in relatively large amounts of vigorous physical activity tended to have a better cardiovascular fitness than those who did not. Children and adolescents who are physically active have less chances of being suffered from multiple cardiovascular risk factors. Nervous health of children and adolescents can also be improved through participating in physical activities by enhancing learning, memory and cognitive ability. Apart from this, physical activities also have a therapeutic property as it helps in reducing stress, anxiety, depression, panic attacks, phobia and so on. Physical activity also boosts the number of hormones circulating in our body in children and adolescents that effects the growth and development. Increase in muscular strength can be achievable by engaging the children in physical exercises as most muscle growth occurs during puberty and is stimulated by physical activity. We can assess the growth and development of children and adolescent with the help of many anthropometric measures such as body mass index, weight \& height of child (growth pattern) and different body parts circumferences. To maximize influence, parents have to provide such environment to their child which gives an opportunity for participating in physical activities. Creating positive habits early in childhood can last a lifetime [73]. Finally, more work needs to be done in order to clarify the physiological basis of growth and development in children and adolescent in context to physical activity. To conclude, it could be said that "Sweat is the Most Effective Medicine for Future Shock".

\section{References}

[1] Growth and Development, retrieved on $30^{\text {th }}$ June, 2014 from http://www.advocatesforyouth.org/growth-and-development-home.

[2] Stang J and Story M (eds), Guidelines for Adolescent Nutrition Services (2005), retrieved on $30^{\text {th }}$ June, 2014 from http://www.epi.umn.edu/let/pubs/adol_book.shtm.

[3] Kazimierczak P, "Physical activity—helping children grow", Everyday Learning Series, 2012; 10 (2): 3.

[4] Physical Activity, retrieved on $05^{\text {th }}$ July, 2014 from http://www.who.int/topics/physical_activity/en/.

[5] Stang J, Story M and Kossover R, Guidelines for Adolescent Nutrition Services (2005),retrieved from http://www.epi.umn.edu/let/pubs/adol-book.shtm.

[6] Meen HD andOseid S., "Physical activity in children and adolescents in relation to growth and development", Scandinavian Journal of Social Medicine, Suppl. 1982; 29: 121-34.

[7] Borms J., “Children and exercise: an overview”,Journal of Sports Science, 1986; 4: 3-20.

[8] Mein HD andOseid S.,"Physical activity in children and adolescents in relation to growth and development”,Scandinavian Journal of Social Medicine, 1982; 9 Suppl. 2: 121-34.

[9] Hills AP, King NA and Armstrong TP, "The contribution of physical activity and sedentary behaviours to the growth and development of children and adolescents: implications for overweight and obesity”, Sports Med., 2007; 37(6):533-45.

[10] Telama R, Yang X, Laakso L, et al., "Physical activity in childhood and adolescence as a predictor of physical activity in young adulthood”,Am J Prev Med, 1997; 13: 317-23.

[11] Telama R, Yang X, Viikari J, et al.,"Physical activity fromchildhood to adulthood: A 21 year tracking study”,Am J Prev Med, 2005; 28 (3): 267-73.

[12] Tammelin T, Nayha S, Hills A, et al., " Adolescent participation insports and adult physical activity.”,Am J Prev Med, 2003; 24: 22-8.
[13] RosenbloomAL., "The Physiology of Human Growth: A Review", Review of Endocrinology, July 2008 (Retrieved on 06th July, 2014 from

http://bmctoday.net/reviewofendo/2008/07/article.asp?f=review07 08_06.php).

[14] Roemmich JN and Rogol AD., "Physiology of growth and development-Its relationship to performance in the young athlete", Clin Sports Med., 1995 Jul; 14(3):483-502.

[15] Obesity, retrieved on Nov. $28^{\text {th }}, 2013$ from http://www.who.int/topics/obesity/en/.

[16] Must A, Jacques PF, Dallal GE, Bajema CJ and Dietz WH., "Long-term morbidity and mortality of overweight adolescents: A follow-up of the Harvard Growth Study of 1922 to 1935”,New England Journal of Medicine, 1992, 327(19):1350-1355.

[17] Epstein LH, Woodall K, Goreczny A. J., Wing R. R. andRoberton R. J., "The modification of activity patterns and energy expenditure in obese young girls, Behaviour Therapy, 1984, 5: 101-8.

[18] Forbes G. B, "Human body composition, New York: Springer(1987).Hagberg, J. M., Exercise fitness \& hypertension (1990), In Bourchard C, Shephard R. J, Stephens T., Stutton J. R. \& Mepheson B. D.(Eds.) Exercise, fitness and health.

[19] Raj Manu and R. Krishna Kumar, "Obesity in children \& adolescents”, Indian J Med Res. Nov 2010; 132(5): 598-607.

[20] Daniels Stephen R., K. Arnett Donna, H. EckelRobert, S. Gidding Samuel, Laura L., Hayman ShirikiKumanyika, Robinson Thomas N., Scott Barbara J., JeorSachiko St. and Williams Christine L., "Overweight in children and adolescents: pathophysiology, consequences, prevention, and treatment”, Circulation, 2005, 111(15): 1999-2012.

[21] Wechsler Howell, McKenna Mary L., Lee Sarah M. and Dietz William H., The Role of Schools in Preventing Childhood Obesity, The State Education Standard, December 2004; Retrieved on $07^{\text {th }}$ July, 2014 from

http://www.cdc.gov/healthyyouth/physicalactivity/pdf/roleofschoo ls_obesity.pdf.

[22] Epstein LH, Myers MD, Raynor HA and Saelens BE, "Treatment of pediatric obesity”, Pediatrics, 101(3/2), 1998: 554-570.

[23] Heinonen A.,"Exercise as an osteogenic stimulus [PhD thesis],Jyvaskyla, Finland: University of Jyvaskyla, 1997.

[24] SlemendaCharles W., ReisterTerry K., HuiSiu L., Miller Judy Z., Christian Joe C. and C. Conrad Johnston, "Influences on skeletal mineralization in children and adolescents: Evidence for varying effects of sexual maturation and physical activity", The Journal of Pediatrics, Volume 125, Issue 2, August 1994: 201-207.

[25] Wendy M. Kohrt, Susan A. Bloomfield, Kathleen D. Little, Miriam E. Nelson and Vanessa R. Yingling, Physical Activity and Bone Health, March 01, 2010(Retrieved on 07 July, 2014 from http://www.medscape.com/viewarticle/717045).

[26] Karlsson, M., "Has exercise an antifracture efficacy in women?”, Scandinavian Journal of Social Medicine, 2004. 14(1): 2-15.

[27] Bailey, D.A., et al., "A Six-Year Longitudinal Study of the Relationship of Physical Activity to Bone Mineral Accrual in Growing Children: The University of Saskatchewan Bone Mineral Accrual \&nbsp Study”,Journal of Bone and Mineral Research, 1999, 14(10): 1672-1679.

[28] Hind K. and Burrows M., "Weight-bearing exercise and bone mineral accrual in children and adolescents: a review of controlled trials", Bone, 2007, 40(1): 14-27.

[29] Physical activity and its role in the prevention of osteoporosis in women, January 2009, Retrieved on 07th July, 2014 from http://www.medibank.com.au/Client/Documents/Pdfs/Osteoporosi s_Health_Booklet.pdf

[30] Urbina EM, Gidding SS, Bao W, et al., "Association of fasting blood sugarlevel, insulin level, and obesity with left ventricular mass in healthychildren and adolescents: the Bogalusa Heart Study”, Am Heart Journal, 1999, 138(1 pt 1):122-127.

[31] Hamilton MT, Hamilton DG and Zderic TW.,"Exercise physiology versus inactivity physiology: an essential concept for understanding lipoprotein lipase regulation”,Exerc Sport Sci, Rev 2004; 32 (4): 161-6.

[32] Haskell WL.,"Health consequences of physical activity: understanding and challenges regarding dose response”,Med Sci Sports Exerc, 1994; 26: 649-60.

[33] Sallis JF, "Epidemiology of physical activity and fitness in children and adolescents”, Crit Rev Food SciNutr, 1993; 33(4-5): 403-8. 
[34] StrongWilliam B.,MalinaRobert M., Cameron J.R.,Blimkie, Stephen R. Daniels,Rodney K. Dishman, Bernard Gutin,Albert C. Hergenroeder, Aviva Must, Patricia A. Nixon, James M. Pivarnik, Thomas Rowland,StewartTrost and François Trudeau, "Evidence Based Physical Activity for School-age Youth", The Journal of Pediatrics, Volume 146, Issue 6, June 2005: 732-737.

[35] ForwoodMark R. and Burr David B., "Physical activity and bone mass: exercises in futility?”,Bone and Mineral, 21 (2), 1993: 89112.

[36] Curry, J. D. \& Butler, G., "The mechanical properties of bone tissue in children”, Journal of Bone and Joint Surgery, 57: 810-17.

[37] Fogelholm M., "How physical activity can work?", Int J PediatrObes, 2008;3 Suppl 1: 10-4.

[38] RogolAD, Clark PA, and RoemmichJ N, "Growth and pubertal development in children and adolescents:effects of diet and physical activity”, American Journal of Clinical Nutrition, 2000; 72(suppl): 521S-8S.

[39] Angold A., Erkanli A., Silberg J., Eaves L. and Costello E.J.,"Depression scale scores in 8-17-year-olds: effects of age and gender”,Journal of Child Psychology and Psychiatry, 2002;43(8):1052-63.

[40] Angold A., Costello E.J. and Worthman C.M.,"Puberty and depression: the roles ofage, pubertal status and pubertal timing”, Psychological Medicine, 1998;28(1):51-61.

[41] Taylor CB, Sallis JF and Needle R.,"The relation of physical activity and exercise to mental health”, Public Health Rep., 1985; 100: 195-202.

[42] Physical Activity Guidelines Advisory Committee Report, 2008. Washington, DC: U.S. Department of Health and Human Services; 2008.

[43] Anxiety, retrieved on $10^{\text {th }}$ July, 2014 from http://keltymentalhealth.ca/mental-health/disorders/anxietychildren-and-youth\#view-tabs-1.

[44] Dishman RK.,"Mental health. In: Seefeldt VS, editor. Physical Activity and Well-being. Reston: American Alliance for Health, Physical Education, Recreation and Dance; 1986: 303-41.

[45] Morgan WP.,"Psychologic benefits of physical activity. In: Nagle FJ, Montoye HJ, editors. Exercise in Health and Disease. Springfield: Charles C Thomas; 1981: 299-314.

[46] SattelmairJacob and RateyJohn J., "Physically Active Play and Cognition-An Academic Matter?”,American Journal of Play, Winter 2009: 365-74

[47] The Benefits of Exercise on Your Kid's Brain, retrieved on $10^{\text {th }}$ July, 2014 from http://www.raisesmartkid.com/3-to-6-years-old/4articles/35-the-benefits-of-exercise-on-your-kids-brain

[48] Physical Activity and Learning, Summary, Status Review, October 2012, Finnish National Board of Education, retrieved on $09^{\text {th }}$ July, 2014 from

http://www.oph.fi/download/145366_Physical_activity_and_learni ng.pdf

[49] University of Illinois at Urbana-Champaign. "Children's brain development is linked to physical fitness, research finds", ScienceDaily, 16 September 2010, retrieved on $09^{\text {th }}$ July, 2014 from www.sciencedaily.com/releases/2010/09/100915171536.htm

[50] Sage GH, "The effects of physical activity on the social development of Children”, In: Stull GA, Eckert HM, editors. Effects of Physical Activity in Children. Champaign: Human Kinetics; 1986. pp. 22-9.

[51] Endocrine System Function, retrieved on 06th July, 2014 from http://www.md-health.com/Endocrine-System-Function.html

[52] Riddell Michael C., "The endocrine response and substrate utilization during exercise in childrenand adolescents", Journal of Applied Physiology, 105, 2008: 725-733.

[53] Cavazos M., Effects of Exercise on Endocrine System, retrieved on 06th July, 2014 from http://www.livestrong.com/article/405612-effects-of-exercise-onendocrine-system/

[54] NabkasornC, MiyaiN, SootmongkolA, Junprasert S, Yamamoto H, AritaM and Miyashita K, "Effects of physical exercise on depression, neuroendocrine stress hormones and physiological fitness in adolescent females with depressive symptoms", European Journal of Public Health,2006, Volume 16, Issue 2: 179184.

[55] KostkaT., "Aging and so called "youth hormones" Potential influence of exercise training," PrzegladLekarski, 2001, vol. 58, no. 1: 25-27.
[56] AmbrosioM. R., ValentiniA., TrasforiniG. et al., "Function of the GH/IGF-1 axis in healthy middle-aged male runners," Neuroendocrinology, 1996, vol. 63, no. 6: 498-503.

[57] HurelS. J., KoppikerN., Newkirk J. et al., "Relationship of physical exercise and ageing to growth hormone production," Clinical Endocrinology, 1999, vol. 51, no. 6: 687-691.

[58] TissandierO., Peres G., FietJ., and PietteF., "Testosterone, dehydroepiandrosterone, insulin-like growth factor 1 , and insulin in sedentary and physically trained aged men,” European Journal of Applied Physiology, 2001, vol. 85, no. 1-2: 177-184.

[59] RavagliaG., FortiP., MaioliF. et al., "Regular moderate intensity physical activity and blood concentrations of endogenous anabolic hormones and thyroid hormones in aging men," Mechanisms of Ageing and Development, 2001, vol. 122, no. 2, pp. 191-203.

[60] Chahal, H. S. and Drake W. M., "The endocrine system and ageing,” Journal of Pathology, 2007, vol. 211, no. 2, pp. 173-180.

[61] CazorlaG, Physical Activity and Child Development, Objectif Nutrition,79 (April 2006), retrieved on 06 $6^{\text {th }}$ July, 2014 from http://www.danoneinstitute.org/objective_nutrition_newsletter/on7 9.php.

[62] Jackson AW, Morrow JR, Hill DW andDishman RK, Physical Activity for Health and Fitness, Champaign: Human Kinetics, 1999.

[63] Cerny FJ and Burton HW.,Exercise Physiology for Health CareProfessionals, Champaign: Human Kinetics, 2001.

[64] Physical Activity Guidelines for Children and Adolescents (Ages 6-17), retrieved on $09^{\text {th }}$ July, 2014 from http://www.sde.ct.gov/sde/lib/sde/PDF/DEPS/Student/NutritionEd /CCAG_AppendixH.pdf.

[65] Elder GC and Kakulas BA, Histochemical and contractile property changesduring human muscle development,Muscle Nerve,1993, 16: 1246-1253.

[66] Physical Activity for Children and Young People, retrieved on $09^{\text {th }}$ July, 2014 from

file:///C:/Users/pradeepsinghc/Downloads/children_and_yp_evide nce_briefing.pdf.

[67] World Health Organization, Physical Status: The Use and Interpretation of Anthropometry. Report of a WHO Expert Committee. WHO Technical Report Series no. 854. Geneva: WHO, (1995).

[68] Kontio M, "Effects of maturation and physical activity on muscle mass and strength in prepubertal girls during two-year follow-up", Master's Thesis in Sports Medicine, Department of Health Sciences, University of Jyväskylä, Spring 2005.

[69] VidmarS, Carlin J, and Hesketh K, "Standardizing anthropometric measures in children and adolescents with new functions for egen", The Stata Journal, 2004 4, Number 1: 50-55.

[70] Semiz S, Ozgören E andSabir N., "Comparison of ultrasonographic and anthropometric methods to assess body fat in childhood obesity”, Int J Obes (Lond), 2007 Jan; 31(1): 53-8.

[71] Woodruff BA and Duffield A, "Anthropometric assessment of nutritional status in adolescent populations in humanitarian emergencies”, European Journal of Clinical Nutrition, 2002, 56 (11): 1108-1118.

[72] WHO Child Growth Standards: Head circumference-for-age, arm circumference-for-age, triceps skinfold-for-age and subscapular skinfold-for-age Methods and development, World Health Organization, Department of Nutrition for Health and Development, retrieved on $09^{\text {th }}$ July, 2014,

http://www.who.int/childgrowth/standards/second_set/technical_r eport_2.pdf.

[73] Chahar PS, "Physical Activity: A Key for the Preclusion of Obesity inChildren”,American Journal of Sports Science and Medicine, 2014, vol. 2, no. 1: 27-31.

[74] Cole TJ, BellizziMC, FlegalKM, and Dietz WH, "Establishing a standard definition for child overweight and obesity worldwide: international survey”,British Medical Journal, 2000, 320(7244): 1240-1243.

[75] Tanner JM and Preece MA, The Physiology of Human Growth, Cambridge University Press, 1989.

[76] Steinberger J and Daniels SR., "Obesity, insulin resistance, diabetes, and cardiovascular risk in children: an american heart association scientific statement from the atherosclerosis, hypertension, and obesity in the young committee (council on cardiovascular disease in the young) and the diabetes committee (council on nutrition, physical activity, and metabolism)", Circulation, 2003, 107: 1448-1453. 
[77] P. HillsAndrew,A. KingNeil and P. ArmstrongTimothy, "The contribution of physical activity and sedentary behaviours to the growth and development of children and adolescents implications for overweight and obesity”, Sports Med, 2007; 37 (6): 533-545.

[78] NiemanPeter, Psychosocial aspects of physical activity”, Paediatr Child Health, 2002 May-Jun, 7(5): 309-312.

[79] Theintz G, Ladame F, Howald H, Weiss U, Torresani $T$ and Sizonenko PC, “The child, growth and high-level sports”, Schweiz Z Med Traumatol, 1994, (3):7-15.

[80] Chatterjee Sridip and MondalSamiran, "Effect of regular yogic training on growth hormone and dehydroepiandrosterone sulfate as an endocrine marker of aging”, Evidence-Based Complementary and Alternative Medicine, Volume 2014 (2014), Article ID 240581: 01-15

[81] Grund A, Dilba B, Forberger K, Krause H, Siewers M, Rieckert H and Muller MJ, "Relationships between physical activity, physical fitness, muscle strength and nutritional state in 5- to 11-year-old children”, Eur J ApplPhysiol, 2000, 82: 425-438.

[82] OnisMercedes de, OnyangoAdelheid, BorghiElaine, SiyamAmani, BlossnerMonika and LutterChessa, "Worldwide implementation of the WHO Child Growth Standards”, Public HealthNutrition, 2012, 15(9): 1603-10. 